\title{
NEED OF EDUCATIONAL TECHNOLOGY TOOLS FOR COGNITIVE DEVELOPMENT IN INTELLECTUALLY DISABLED CHILDREN
}

\author{
Savitha Korattikkara Kumaran ${ }^{1}$ and Renumol Vempalively Govindapillai ${ }^{2}$ \\ Cochin University of Science and Technology, Kerala, India \\ ${ }^{1}$ Research Scholar \\ ${ }^{2}$ Professor
}

\begin{abstract}
Research on special education has showed that the use of digital technology for the special need children can help to simplify their educational process. Intellectual disability (ID) is a kind of developmental disorder. ID children need some kind of scaffolding during their learning process. Hence, as part of our ongoing research to design and develop an AR-based educational technology (ET) tool for ID children, we have conducted 3 studies. This paper describes our findings from these studies. Initially we have conducted a pilot study to investigate how Augmented Reality (AR) based educational application would help the mild and moderate ID children in learning English alphabets. Then we have conducted a survey to know the concern of special teachers about technology tools for ID children. In the third study, we have visited some of the special schools in Kerala to know more about the issues pertaining to the ID children. The results of these 3 studies warrant the need to design and develop some kind of AR/VR application for educating ID children.
\end{abstract}

\section{KEYWORDS}

Special Need Children, Augmented Reality (AR), Intellectual Disability (ID), Educational Technology (ET) Tool, Virtual Reality (VR)

\section{INTRODUCTION}

Typically, education is the primary process to gain knowledge, skills and moral values for school-going children. Like ordinary children, Special Education Needs (SEN) children also deserve inclusion into the education system. Studies in the field of special education show that the learning difficulties of the children with disabilities are tough to recognize in the initial stage. They may show extreme impatience, deficiency in thinking capacity, lack of concentration on studies etc. at various stages. Initially we need to find their academic, social and behavioral problems and take appropriate measures to design suitable didactic settings (Bakken et al, 2017). There are many hurdles in providing didactic settings for the special need children, such as designing and developing interventions to facilitate their learning process, dedicated teachers to scaffold, developing the habit of using technology etc. (Jadán-Guerrero and Guerrero, 2015). Investigations in the education arena showed that the deficiency of time and resources led to the shortage of technology tools usages in schools (Schoepp, 2005). However, the use of digital technology for the special need children can help to simplify their educational process.

In our study we have focused only on the children with intellectual disability (ID). ID is a developmental problem. It consists of genetic and atmospheric factors (Daily, 2000). It is described by an IQ test. If the IQ test value is under 70, it is confirmed as intellectual disability. If the value is in the range from 51 to 70 , then it is considered as mild ID and from 35 to 50 is recognized as moderate ID ("Mental Retardation", 2020). Mild group of children are poor in their educational activities whereas children with moderate ID require more specific attention even in their social life. Since the academic talent of ID children is limited, they need some kind of scaffolding during their learning process. 
From the literature, it is learned that the learning process of the ID children is very challenging and they require more supportive and attractive learning materials. In this circumstance, it is found that there is a lot of scope for the innovative technology tools. So the recognition of various procedures and informative applications is important for the innovative development in the education system for SEN children (Edyburn, 2013). Educators are more responsible for integrating technologies into such informative applications (Baglama et al, 2017). Researchers assured that, using technological applications for the students with special needs is more influential in their educational progresses (Michaels and McDermott, 2003) (Schlosser and Wendt, 2008). A study on Information and Communication Technology (ICT) in special education has mentioned that ICT has the potential to balance and bring SEN children to the mainstream (Istenic Starcic and Bagon, 2014). Integration of ICT as an innovative mechanism in the classroom can improve the teaching learning practice (Sangrà and González-Sanmamed, 2010) and also the student's responsiveness in class (Hennessy et al, 2005). However, there are lot of obstacles in integrating ICT, such as teacher training, different viewpoints associated with the assessment process and organization of the resources, time limitations of the instructors etc. (Copley and Ziviani, 2004). Even though, the situation will be changed by the optimistic educational improvements associated with the incorporation of technology-based tools for the students with diverse population (Connor et al, 2010). And also the effective usages of ICT tools will inspire the special need children in the classroom atmosphere (Williams, 2006). One such technology is Augmented Reality (AR). It is a developing technology that may support students to acquire information through the collaboration of computer-generated entities in the actual atmosphere. AR has the capacity to engage and inspire students in the controlled, school environment. It permits students to realize the physical objects, which means that it complements realism than entirely changing it (Agarwal and Thakur, 2014).

AR provides the life-like experience for the students by the 3D hallucination of various things, which helps them to visualise things. Using $\mathrm{AR}$ as the instructional method, a teacher can demonstrate $3 \mathrm{D} / 4 \mathrm{D}$ interpretation of entities to students, different from the conventional method in the classroom (Saidin et al, 2015). AR has the ability to support students to accomplish subject awareness and endure that knowledge uninterruptedly by the communication with a smartphone. AR in portable devices proposes a countless potential in the teaching learning process (Hwang et al, 2016). So in this paper we describe our studies conducted to understand the necessity of technology based tools for the cognitive development of ID children.

\section{METHODOLOGY}

We have conducted three studies to understand the need of technology tools for improving the social and academic activities of the Intellectually Disabled (ID) children. First one was a pilot study to investigate how Augmented Reality (AR) based educational application would help the mild and moderate ID children in learning English alphabets. The second was a survey to know the concern of special teachers about technology tools for the ID children. The third study was conducted to know more about the issues pertaining to the ID children. For this we have visited some of the special schools in Kerala and interacted with the teachers and parents. The following sections describe these studies, our observations and findings.

\subsection{A Pilot Study Using AR-Based Educational Application}

As mentioned earlier, in order to achieve the required learning outcome, the ID children need some kind of cognitive support. So we have conducted a pilot study to investigate how Augmented Reality (AR) based educational application would help the mild and moderate ID children in learning English alphabets (Savitha and Renumol, 2019). A comparative study was conducted to check the impact of the application. Eight ID children were participated in this study. They were divided into two groups. Children with hyperactivity were grouped as the experimental group, and they had more backing from AR-based tool via smartphone, whereas the control group learners have learned in the traditional mode. After assessing the parameters such as the learning outcome, response to the learning material, learning time and the memory capacity, it has been observed that the students from the experimental group showed progress in all the parameters than those in the control group. So we got an insight that the AR-based application has a hopeful influence on ID children. With the usage of this innovative technology, the resource teachers and parents could develop their children's responsiveness and curiosity to the class session compared to the traditional way of coaching. By using the AR 
tool, the resource teacher could prove that the topics incorporated with the smartphone could influence the children's concern in the learning activities. After this pilot study, we can say that AR has enough potential to be integrated in to the education system of the students with ID. Hence the upcoming expansions of the AR technology can be incorporated into the special education.

\subsection{A Survey Based Analysis}

Listening to the end users is important in software development to collect the requirements. Since our aim is to design and develop an AR-based tool for the ID children, we wanted to hear the concerns of the special teachers about technology use in the classroom. We consider teachers as our clients because we can understand the concerns and collect the requirements about technological tools for the ID children only through the interaction with the teachers. So we have conducted a survey among a set of special teachers from Kerala. The aim of the survey was to know the concern of those teachers about technology tools for ID children.

The instrument for the survey was based on the Stages of Concern Questionnaire (SoCQ) and it was designed by referring the paper "Measuring the stages of concern about an innovation: A manual for use of the stages of concern questionnaire" (Hall et al, 1977). It is a manual for the use of the SoC Questionnaire. The questionnaire included 35 items related to technology and 6 items related to demographic information. The questionnaire is available for reference in Appendix.

Each question was represented in a 7 point Likert scale (0-6 points) as shown below:

Unconcerned (0), Informational (1), Personal (2), Management(3),Consequence(4), Collaboration(5) and Refocusing(6).

Hundred and four resource teachers from different schools have participated in this survey. They were educationally trained teachers (B.Ed. and M.Ed. in Special Education) for handling special need children. Their responses indicated that, they are interested to learn more about technological tools to teach ID children. They expressed that they need an alternative method of teaching as well as teaching materials apart from which they are currently using.

\subsection{Visit to Special School}

Apart from these studies, we have also visited some of the special schools in Kerala to know more about the issues pertaining to ID children. Visits were mainly concerned about interacting with the teachers and parents to know the daily activities of ID children. From these visits we came to know that, children with ID have complicated problems in their daily life. In some schools, we have noticed that there are anecdotal evidences of positive impact on ID children while using technological tools for training. Teachers from one of the schools we have visited informed that, by using a Virtual Reality (VR) application one of the ID children improved his gross motor skill. Through the daily usage of that particular application he was able to climb stairs, which was an impossible task for that child. He was not able to take a step without the help of somebody. With the help of that VR application he could walk independently. From the interaction, we have observed that the teachers and the parents are more enthusiastic about AR/VR applications and generally, the possibility of integrating technological tools for the disabled children.

\section{CONCLUSION}

This study focuses on the necessities and advantages of ET tools for the special need children, specifically for the ID children. ID children need some kind of scaffolding during their learning process. They need some kind of cognitive support to achieve the learning outcome. Researchers in the field of special education stated that the learning process of ID children is very challenging and they require more cooperative and attractive learning materials. In this condition, using AR as an educational tool may make much more improved results in their motor skills and also in their cognitive abilities. So we have conducted 3 studies to know about the relevance and concerns of integrating ET tools in special education. Our observations from these studies indicated the relevance of ET tools for developing the cognitive skills of the ID children. From the observed results, we have reached a conclusion that, development of AR based educational applications for the ID children has potential to explore further. 


\section{ACKNOWLEDGEMENT}

We express our sincere gratitude to the participants and their parents who have patiently participated in our pilot study. We wholeheartedly appreciate the support given by the District Program Officers, the Block Program Officers and the Heads of various Schools from the districts Kozhikode, Ernakulam and Thrissur of Kerala, India, to carry out our studies. We also thank the teachers from various schools of Kerala, who have participated in our survey.

\section{REFERENCES}

Agarwal, C., \& Thakur, N. (2014). The evolution and future scope of augmented reality. International Journal of Computer Science Issues (IJCSI), 11(6), 59.

Baglama, B., Yikmis, A., \& Demirok, M. S. (2017). SPECIAL EDUCATION TEACHERS'VIEWS ON USING TECHNOLOGY IN TEACHING MATHEMATICS. European Journal of Special Education Research.

Bakken, L., Brown, N., \& Downing, B. (2017). Early childhood education: The long-term benefits. Journal of research in Childhood Education, 31(2), 255-269.

Connor, C., Snell, M., Gansneder, B., \& Dexter, S. (2010). Special education teachers' use of assistive technology with students who have severe disabilities. Journal of Technology and Teacher Education, 18(3), 369-386.

Copley, J., \& Ziviani, J. (2004). Barriers to the use of assistive technology for children with multiple disabilities. Occupational Therapy International, 11(4), 229-243.

Daily, DK, Ardinger, HH, \& Holmes, GE (2000). Identification and evaluation of mental retardation. American family physician, 61(4), pp. 1059-1067.

Edyburn, D. L. (2013). Critical issues in advancing the special education technology evidence base. Exceptional Children, $80(1), 7-24$.

Hall, G. E., George, A. A., \& Rutherford, W. L. (1977). Measuring the stages of concern about an innovation: A manual for use of the stages of concern questionnaire. Austin: Research and Development Center for Teacher Education, The University of Texas.

Hennessy, S., Ruthven, K., \& Brindley, S. U. E. (2005). Teacher perspectives on integrating ICT into subject teaching: commitment, constraints, caution, and change. Journal of curriculum studies, 37(2), 155-192.

"Mental Retardation." International Encyclopedia of the Social Sciences. Retrieved August 11, 2020 from Encyclopedia.com:https://www.encyclopedia.com/social-sciences/applied-and-social-sciences-magazines/mentalretardation-0

Hwang, G. J., Wu, P. H., Chen, C. C., \& Tu, N. T. (2016). Effects of an augmented reality-based educational game on students' learning achievements and attitudes in real-world observations. Interactive Learning Environments, 24(8), 1895-1906.

Istenic Starcic, A., \& Bagon, S. (2014). ICT-supported learning for inclusion of people with special needs: Review of seven educational technology journals, 1970-2011. British Journal of Educational Technology, 45(2), 202-230.

Jadán-Guerrero, J., \& Guerrero, L. A. (2015). A virtual repository of learning objects to support literacy of SEN children. IEEE Revista Iberoamericana de Tecnologias del Aprendizaje, 10(3), 168-174.

Michaels, C. A., \& McDermott, J. (2003). Assistive technology integration in special education teacher preparation: Program coordinators' perceptions of current attainment and importance. Journal of Special Education Technology, 18(3), 29-44.

Saidin, N. F., Halim, N. D. A., \& Yahaya, N. (2015). A review of research on augmented reality in education: Advantages and applications. International education studies, 8(13), 1-8.

Sangrà, A., \& González-Sanmamed, M. (2010). The role of information and communication technologies in improving teaching and learning processes in primary and secondary schools. ALT-J, 18(3), 207-220.

Savitha, K. K., \& Renumol, V. G. (2019) Effects of Integrating Augmented Reality in Early Childhood Special Education, International Journal of Recent Technology and Engineering, 8(3), pp. 7864-7867.

Schlosser, R. W., \& Wendt, O. (2008). Effects of augmentative and alternative communication intervention on speech production in children with autism: A systematic review. American journal of speech-language pathology.

Schoepp, K. (2005). Barriers to technology integration in a technology-rich environment. Learning and teaching in higher education: Gulf perspectives, 2(1), 1-24.

Williams, P., Jamali, H. R., \& Nicholas, D. (2006, July). Using ICT with people with special education needs: what the literature tells us. In Aslib Proceedings. Emerald Group Publishing Limited. 


\section{APPENDIX}

\begin{tabular}{|c|c|c|c|}
\hline 0 & 12 & $\begin{array}{lll}3 & 4 & 5\end{array}$ & 6 \\
\hline Irrelevant & Not true of me now & Somewhat true of me now & Very true of me now \\
\hline
\end{tabular}

\begin{tabular}{|c|c|c|c|c|c|c|c|c|c|}
\hline 1. & $\begin{array}{l}\text { I am concerned about students' attitudes toward the } \\
\text { technology. }\end{array}$ & 0 & 1 & 2 & 3 & 4 & 5 & 6 & 7 \\
\hline 2. & $\begin{array}{l}\text { I now know of some other approaches that might work } \\
\text { better. }\end{array}$ & 0 & 1 & 2 & 3 & 4 & 5 & 6 & 7 \\
\hline 3. & I am more concerned about another technology. & 0 & 1 & 2 & 3 & 4 & 5 & 6 & 7 \\
\hline 4. & $\begin{array}{l}\text { I am concerned about not having enough time to organize } \\
\text { myself each day. }\end{array}$ & 0 & 1 & 2 & 3 & 4 & $J$ & 6 & 7 \\
\hline 5. & $\begin{array}{l}\text { I would like to help other faculty in their use of the } \\
\text { technology. }\end{array}$ & 0 & 1 & 2 & 3 & 4 & $J$ & 6 & 7 \\
\hline 6. & I have a very limited knowledge of the technology & 0 & 1 & 2 & 3 & 4 & 5 & 6 & 7 \\
\hline 7. & $\begin{array}{l}\text { I would like to know the effect of reorganization on my } \\
\text { professional status. }\end{array}$ & 0 & 1 & 2 & 3 & 4 & $J$ & 6 & 7 \\
\hline 8. & $\begin{array}{l}\text { I am concerned about conflict between my interests and my } \\
\text { responsibilities. }\end{array}$ & 0 & 1 & 2 & 3 & 4 & $J$ & 6 & 7 \\
\hline 9. & I am concerned about revising my use of the technology. & 0 & 1 & 2 & 3 & 4 & 5 & 6 & 7 \\
\hline 10. & $\begin{array}{l}\text { I would like to develop working relationships with both our } \\
\text { faculty and outside faculty using this technology. }\end{array}$ & 0 & 1 & 2 & 3 & 4 & 5 & 6 & $\overline{7}$ \\
\hline 11. & I am concerned about how the technology affects students. & 0 & 1 & 2 & 3 & 4 & 5 & 0 & 7 \\
\hline 12. & I am not concerned about the technology at this time. & 0 & 1 & 2 & 3 & 4 & 5 & 6 & 7 \\
\hline 13. & $\begin{array}{l}\text { I would like to know who will make the decisions in the new } \\
\text { system. }\end{array}$ & 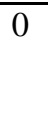 & 1 & 2 & 3 & 4 & 5 & 0 & 7 \\
\hline 14. & $\begin{array}{l}\text { I would like to discuss the possibility of using the } \\
\text { technology. }\end{array}$ & 0 & 1 & 2 & 3 & 4 & 5 & 6 & $\overline{7}$ \\
\hline 15. & $\begin{array}{l}\text { I would like to know what resources are available if we } \\
\text { decide to adopt the technology. }\end{array}$ & 0 & 1 & 2 & 3 & 4 & 5 & 6 & 7 \\
\hline 16. & $\begin{array}{l}\text { I am concerned about my inability to manage all that the } \\
\text { technology requires. }\end{array}$ & 0 & 1 & 2 & 3 & 4 & 5 & 6 & $\bar{~} 7$ \\
\hline 17. & $\begin{array}{l}\text { I would like to know how my teaching or administration is } \\
\text { supposed to change. }\end{array}$ & 0 & 1 & 2 & 3 & 4 & 5 & 6 & 7 \\
\hline
\end{tabular}




\begin{tabular}{|c|c|c|c|c|c|c|c|c|c|}
\hline 18. & $\begin{array}{l}\text { I would like to familiarize other departments or persons } \\
\text { with the progress of this new approach. }\end{array}$ & 0 & 1 & 2 & 3 & 4 & 5 & 6 & 7 \\
\hline 19. & I am concerned about evaluating my impact on students. & 0 & 1 & 2 & 3 & 4 & 5 & 6 & 7 \\
\hline 20. & I would like to revise the technology's approach. & 0 & 1 & 2 & 3 & 4 & 5 & 6 & 7 \\
\hline 21. & I am preoccupied with things other than the technology. & 0 & 1 & 2 & 3 & 4 & 5 & 6 & 7 \\
\hline 22. & $\begin{array}{l}\text { I would like to modify our use of the technology } \\
\text { based on the experiences of our students. }\end{array}$ & 0 & 1 & 2 & 3 & 4 & 5 & 6 & 7 \\
\hline 23. & I spend little time thinking about the technology. & 0 & 1 & 2 & 3 & 4 & 5 & 0 & 7 \\
\hline 24. & $\begin{array}{l}\text { I would like to excite my students about their part in } \\
\text { this approach. }\end{array}$ & 0 & 1 & 2 & 3 & 4 & 5 & 6 & 7 \\
\hline 25. & $\begin{array}{l}\text { I am concerned about time spent working with } \\
\text { nonacademic problems related to the technology. }\end{array}$ & 0 & 1 & 2 & 3 & 4 & 5 & 6 & 7 \\
\hline 26. & $\begin{array}{l}\text { I would like to know what the use of the technology } \\
\text { will require in the immediate future. }\end{array}$ & 0 & 1 & 2 & 3 & 4 & 5 & 6 & 7 \\
\hline 27. & $\begin{array}{l}\text { I would like to coordinate my efforts with others to } \\
\text { maximize the technology's effects. }\end{array}$ & 0 & 1 & 2 & 3 & 4 & 5 & ( & 7 \\
\hline 28. & $\begin{array}{l}\text { I would like to have more information on time and energy } \\
\text { commitments required by the technology. }\end{array}$ & 0 & 1 & 2 & 3 & 4 & 5 & ( & 7 \\
\hline 29. & $\begin{array}{l}\text { I would like to know what other faculty are doing in this } \\
\text { area. }\end{array}$ & 0 & 1 & 2 & 3 & 4 & 5 & 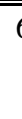 & 7 \\
\hline 30. & $\begin{array}{l}\text { Currently, other priorities prevent me from focusing my } \\
\text { attention on the technology. }\end{array}$ & $\overline{0}$ & 1 & 2 & 3 & 4 & 5 & ( & 7 \\
\hline 31. & $\begin{array}{l}\text { I would like to determine how to supplement, enhance, or } \\
\text { replace the technology. }\end{array}$ & 0 & 1 & 2 & 3 & 4 & 5 & ( & $\overline{7}$ \\
\hline 32. & $\begin{array}{l}\text { I would like to use feedback from students to change the } \\
\text { program. }\end{array}$ & 0 & 1 & 2 & 3 & 4 & 5 & ( & 7 \\
\hline 33. & $\begin{array}{l}\text { I would like to know how my role will change when I am } \\
\text { using the technology. }\end{array}$ & 0 & 1 & 2 & 3 & 4 & 5 & ( & 7 \\
\hline 34. & $\begin{array}{l}\text { Coordination of tasks and people is taking too much of my } \\
\text { time. }\end{array}$ & 0 & 1 & 2 & 3 & 4 & 5 & ( & 7 \\
\hline 35. & $\begin{array}{l}\text { I would like to know how the technology is better than } \\
\text { what we have now. }\end{array}$ & 0 & 1 & 2 & 3 & 4 & 5 & ( & 7 \\
\hline
\end{tabular}




\section{Please complete the following:}

1. How long have you been involved with the technology, not counting this year?

Never 1 year 2 years 3 years 4 years 5 or more

2. In your use of the technology, do you consider yourself to be a: non-user __ novice __ intermediate __ _ old hand __ past user

3. Have you received formal training regarding the technology (workshops, courses)? Yes No

4. Are you currently using any technology tools? Yes No

If yes, please specify the names of the tools:

5. If you have any suggestions about technology usage towards special children, please describe briefly: 